\title{
Educational Leadership Doctoral Students' Perceptions of the Effectiveness of Instructional Strategies and Course Design in a Fully Online Graduate Statistics Course
}

\author{
Mei Jiang, Julia Ballenger, and William Holt \\ Texas A\&M University-Commerce
}

\begin{abstract}
In the past several decades, higher education has witnessed the exponential growth of online learning. New technology has dramatically transformed the way education is delivered compared to what takes place in the traditional classroom. It has enabled online delivery of course materials to students outside of face-to-face classroom in an asynchronous manner and provide them with self-paced flexibility. Given the abstract nature of statistics content, effectiveness of the instructional strategies and course design in online statistics instruction has become particularly important to students' learning success. In this qualitative study, the authors explored perceptions of the Educational Leadership doctoral students towards an online graduate level introductory statistic course in terms of whether the online course instructional strategies and course design helped them learn statistics. The authors assessed effectiveness of the instructional strategies and design of the online statistics course as well as students' needs, so more effective instructional strategies could be used for online statistics teaching. Students identified the PowerPoint presentations with recorded lectures to be the most useful strategy. This strategy, along with live Q\&A sessions and guided practices and activities, helped to connect the textbook information and its application to the real world.
\end{abstract} Education

Keywords: instructional strategy, online course design, statistics, Competency-Based

Jiang, M., Ballenger, J., \& Holt, W. (2019). Educational leadership doctoral students' perceptions of the effectiveness of instructional strategies and course design in a fully online graduate statistics course. Online Learning, 23(4), 296-312. doi:10.24059/olj.v23i4.1568

\section{Educational Leadership Doctoral Students' Perceptions of the Effectiveness of Instructional Strategies and Course Design in a Fully Online Graduate Statistics Course}

Since the first online education program that utilized the U.S. mail in 1982 (Hamilton \& Feenberg, 2012), we have witnessed the exponential growth of online education. According to Babson Survey Research Group, more than 6.3 million students in the U.S. took at least one online course in Fall 2016 (Seaman, Allen, \& Seaman, 2018). Public colleges and universities in the U.S. had a 7.3 percent increase in online course enrollment between fall 2015 and 2016, while private nonprofit schools had a 7.1 percent increase. Internet and digital technologies such as electronic 
mail, Instant Messaging, Interactive video conferencing, mobile/smartphones, and social networks have dramatically transformed the way education is delivered (Cook \& Sonnenberg, 2014; Friedman, 2018). Such new tools have enabled online delivery of course materials to students outside of brick-and-mortar classrooms in an asynchronous manner. In the field of Educational Administration/leadership, students with full-time leadership positions in public education benefit from online programs as they provide self-paced flexibility. Indeed, flexibility and convenience are so important that $40(75.4 \%)$ of 53 doctoral level Educational Leadership programs in public universities in Texas are either $100 \%$ online, fully online ( $86 \%-99 \%$ ), or hybrid/blended/electronic to group (THECB, 2018).

Despite the popularity of online education, past research has noted that online instruction in the field of statistics may not produce comparable performance among lower preforming students as in face-to-face teaching ( $\mathrm{Lu} \&$ Lemonde, 2013). Given the abstract nature of statistics content, near-to-zero or even negative effect sizes were identified in online delivery with computer-assisted instruction (Larwin \& Larwin, 2011). Thus, effectiveness of the instructional strategies and course design of online statistics instruction becomes particularly important to students' learning success. Bonk and Dennen (2003) described instructional strategies as the curriculum and instructional styles and pedagogical means used to guide the development of course content, student engagement, and learning activities. Online course design features such as sequence of course content, communication modes, and assignment structure are considered the most influential factors impacting successful online teaching and learning (Baldwin, 2017). The purpose of this study was to determine how doctoral level students in a fully online Educational Leadership Doctoral program perceived the effectiveness of instructional strategies and course design features of a graduate-level introductory statistics course in a mid-sized, doctoral-granting public institution.

As one of the two required statistics courses in the program, this introductory statistics course covers fundamental statistical concepts and focuses on the application of various statistics tests (i.e., $t$-test, one-way ANOVA, chi-square, correlation, and simple regression) in educational research. In order to prepare students for dissertation and further research, this introductory statistics course adopted the ideology of competency-based learning (Spady, 1977) that focuses on fulfilling clearly defined learning skills and competencies in course design rather than solely learning abstract concepts. Spady defined Competency-Based Education (CBE) as "a data-based, adaptive, performance-oriented set of integrated processes" (p. 10) in an outcome-driven pedagogy. CBE emphasized the importance of clearly defining robust and valid competencies in program development (Johnstone \& Soares, 2014; Rivenbark \& Jacobson, 2014). To create a successful CBE program, learning outcomes are first established, followed by the alignment of instructional pedagogy with outcomes, the development of a structured assessment to evaluate student success and, finally, curriculum adjustments once outcomes are evaluated. When implementing CBE in this online statistics course, the instructor carefully balanced the conceptual knowledge and the acquisition of the skills so that students could master skills to write methodology and data results in their dissertations. Particularly, the Community of Inquiry (COI) Framework (Garrison, Anderson, \& Archer, 2000), the Course Life Cycle and Competency (CLCC) Framework (Shankararaman \& Elmaleh, 2016), and the Quality Matters (QM) standards were used to guide the design of this graduate level online statistics course. 


\section{Review of Literature}

\section{The Community of Inquiry (COI) Framework}

Based on the constructivist theoretical principles, Garrison et al. (2000) proposed the Community of Inquiry (CoI) framework that represents a process of developing a collaborative learning experience as an online learning tool. The CoI framework consists of three elements (social, cognitive, and teaching presence) that takes place in the interaction of individual learners and their instructor, as well as the categories and indicators that are to define each presence and to code the transcripts. The element of social presence was defined by Garrison et al. as "the ability of participants in a community of inquiry to project their personal characteristics into the community, thereby, presenting themselves to others as real people" (p. 89). Effective communication, open communication, and group cohesion are three major aspects of social presence. To achieve educational goals, online course design should create the environment for inquiry to allow quality, open educational communication between learners and the instructor. Different approaches, including reflective discussions, one-on-one, and small group virtual audio and visual venues, can be used to allow for educational interactions. Cognitive presence is "the extent to which the participation in any particular configuration of a community of inquiry are able to construct meaning through sustained communication" (Anderson et al., 2001, p. 12). One way to increase cognitive presence in online courses is to design activities that allow students to work together to understand, explore, solve, and apply problems. Teaching presence denotes the design elements of online course that "allows for instructor facilitation and pedagogical direction to learners in the social and cognitive processes" (Anderson, Rourke, Garrison, \& Archer, 2001, p. 4). Teaching presence has been found to be critical in student satisfaction, perceived learning, and sense of community. Teaching presence is interrelated with social and cognitive presence, and all three elements of CoI work together to build a collaborative and coherent online learning community.

\section{Course Life Cycle and Competency (CLCC) Framework}

Course Life Cycle and Competency (CLCC) Framework (Shankararaman \& Elmaleh, 2016) consists of leveraging learning outcomes and competencies throughout the life cycle of the course to increase students' success. Passow (2012) defined competency as the knowledge, skills, and abilities in the context of a specific subject area or domain to enable students to make decisions or take appropriate actions. Competencies could provide a structured approach for implementing continuous assessment of outcomes (Pinto, 2012). Corresponding to CBE (Spady, 1977), the implementation of the CLCC highlights how competencies are used to drive the development of various phrases of course development. The CLCC framework addresses the following five phases of a course, namely, content design, assessment design, content delivery and assessment, assessment feedback, and content review.

In Content Design Phase, the learning outcomes, unit goals, and objectives are usually included in the syllabus and modules of courses taught. Shankararaman and Elmaleh (2016) reported that the course instructor determined the topics and resources that would provide students the opportunity to master the competencies, assessments, and assignments. The careful selection of course topics and resources is critical to ensure the acquisition of the competencies. In Assessment Design Phase, the assessments are developed. It is important that the set of questions for the assessments, as well as grading scheme and rubrics, be aligned with course competencies. In Content Delivery and Assessment Phase, the instructor prepares course content to be delivered 
through a combination of lectures, discussions, videos, and other modalities. The competencies students are expected to acquire for the content are explicitly described to them. In this way, students know what competencies to acquire and the instructor understands what competencies to assess. In Assessment Feedback Phase, the instructor analyzes the assessment scores and presents feedback to students immediately. Immediacy of feedback is the key. The instructor should provide immediate small group or individual instruction to students who have not attained the competencies measured by this assessment. In the final phase, Content Review Phase, the instructor conducts a thorough analysis of the various assessments in the course and the competencies that have been mastered or not. This review can lead to course content modification, sequence adjustment of content taught, or assessment redesign.

\section{Quality Matters: The Learning-Performance-Design Connection}

Quality Matters is a nationally recognized, faculty-centered, peer process program designed to determine and certify the quality of online courses and learning in the U.S. ("Quality Matters", n.d.). Central to Quality Matters is the concept of alignment, when learning objectives, measurement and assessment, educational materials, interaction and engagement of learners, and course technology work together to ensure achievement of desired learning outcomes. Therefore, the use of QM standards when designing the content and delivery of the online course is essential. The essential components of the QM standards that guide the design of the online statistics course include:

- The instructor's plan for classroom response time and feedback on assignments is clearly stated.

- The requirements for learner interaction are clearly stated.

- The assessments measure the stated learning objectives or competencies.

- The course grading policy is clearly stated.

- Specific and descriptive criteria are provided for the evaluation of learners' work and are tied to the course grading policy.

- The instructional materials contribute to the achievement of the stated course and module/unit learning objectives or competencies (http://www.qmprogram.org/rubric).

\section{Teaching Statistics Online: Instructional Strategies and Course Design}

Empirical research has been conducted on the impact of instructional strategies and technology integration in teaching college statistics (Larwin \& Larwin, 2011; Lu \& Lemonde, 2013; Saadati, Tarmizi, Ayub, \& Bakak, 2015; Sosa, Berger, Saw, \& Mary, 2011). Yang (2017) explored students' perspectives on the effectiveness of online instructional strategies used in a fully online statistics course. Data, in the form of student reflection essays and an anonymous endof-semester course evaluation, were collected from $39 \mathrm{~K}-20$ teachers enrolled in an online statistics course. A deductive approach was used to identify the online instructional strategies and course designs that effectively helped students learn statistical concepts. Results indicated that effective online instructional strategies included case studies, video demonstrations, access to instructor notes, mini projects, and discussion forums. Additional strategies used by students included outside online resources, practicing textbook examples and chapter problems, seeking help from peers, colleagues and friends, and one-on-one discussions with the instructor. A consistent course structure, the variety of resources, and the real-world application cases were also considered helpful and effective. 
Brown and Kass (2009) suggested that statistics instructors consider incorporating a "statistics way of thinking" in teaching statistics. It is not uncommon that students perceive statistics as memorization of "cookbook" methods/statements and rote application of hypothesis statistical procedures. To address such challenges, Horton (2015) proposed three methods: (a) broaden the role of multivariable methods in curricula; (b) develop data-related skills early; and (c) expand the role of simulation and computation.

First, Horton (2015) believed that multivariate ways of statistics thinking, the basics of confounding, and causal inference should be incorporated into course design. Students must be able to understand issues of design, confounding, and bias in order to succeed in statistics learning (Kaplan, 2012). Horton (2013) noted that a major limitation in many statistics courses is a lack of multivariable methods in working on data projects. He posited that students needed to understand design, confounding, and bias from a research design perspective, as these are the competencies that doctoral students need to master in order to design their research and analyze their data in dissertation. Second, Horton urged that data-related skills should be developed early. Students need experience analyzing larger, real-world data sets and to be aware of what techniques do and do not scale well. Similarly, Finzer (2015) noted that students should develop data habits of mind that allow them to think creatively about data and understand conceptions of "data tidying" (Wickham, 2014). When working with data, students must first determine the question, describe a solution in terms that a computer program can understand, and execute the commands to implement the solution. Particularly, doctoral students need to be able to manage challenging data sets of varying sizes and complexity (Horton, Baumer, \& Wickham, 2015). Finally, Horton valued expansion of the role of simulation and computation. Graduate programs should provide a framework that encourages students to learn new topics, methods, and approaches, and to become life-long learners. For example, empirical problem-solving and computational tools should be incorporated into the program curriculum and prepare students to gain competency to find answers to problems.

\section{Statistics Anxiety, Math Anxiety and Immediacy}

Onwuegbuzie (2004) described statistics anxiety as the apprehension that an individual experiences in instructional situations, in assessments related to statistics, or when working on statistical assignments. Statistics anxiety was to a large degree responsible for the maintenance of a high anxiety level, which impaired students' academic performance (Macher, et al., 2013; Onwuegbuzie \& Daley, 1999; Onwuegbuzie, Da Ros, \& Ryan, 1997). Similarly, mathematics anxiety is expressed by feelings of apprehension and increased physiological reactivity when individuals must manipulate numbers and solve mathematical problems (Carey, Hill, Devine, \& Szůcs, 2016; Hopko, Mahadeyan, Bare, \& Hunt, 2003). It has been argued that the contents underlying both types of anxiety came from one domain of knowledge and, therefore, could not be regarded separately. Therefore, statistics anxiety has been treated as an affiliate function of mathematics anxiety. However, other studies considered statistics anxiety as being conceptually different from mathematics anxiety (Baloglu, 2003).

Onwuegbuzie et al. (1997) conducted an in-depth, qualitative study of statistics anxiety to explore graduate students' attitudes and experiences in an intermediate statistics class. The results revealed that students reported psychological symptoms such as depression, frustration, panic, and worry. In fact, Onwuegbuzie (2004) stated that many graduate students delayed enrolling in statistics classes because of their anxiety. Relatedly, instructor immediacy has been found to help alleviate statistics anxiety. Immediacy is the communicative behaviors that influence students' 
perceptions of physical and psychological closeness (Anderson, Norton \& Nussbaum, 1981). Williams (2010) examined the effect of instructor immediacy on students' statistics anxiety in a control group design with 76 graduate students from a variety of academic disciplines enrolled in a graduate-level introductory statistics course. Williams found that instructor immediacy was significantly related to reduction in students' statistics anxiety, explaining between 6 - 20 percent of the variance in students' six factors of anxiety levels, with fear of statistics teachers being the most impacted one. This echoes with Mehrabian's (1971) statement on immediacy principle: "People are drawn toward persons and things they like and avoid things they dislike" (p. 1).

\section{Methods}

In this qualitative study, five reflection questions adopted from Yang (2017) were used to explore students' perceptions about the graduate level introductory statistics course in terms of whether instructional strategies and course design helped them learn statistics. The effectiveness of the current instructional strategies and the needs of students were assessed so that a more effective statistics course design could be adapted. As Spady (1977) noted, CBE programs are never "finally and officially in place and permanent" (p. 12).

\section{Course Design Context}

To better help students build the connection between statistics and actual dissertation research, this introductory statistics course aimed at installing a solid research sense in students so that students could master statistics from a research design perspective (Horton, 2015). CBE development principles were incorporated in this statistics course design (Johnstone, \& Soares, 2014). The first task was to identify robust and valid competencies as the core of CBE curriculum. In this course, identified competencies focused on building research design knowledge base in Unit 1, followed by the SPSS basic descriptive data analysis skills in Unit 2. A series of statistical tests were then introduced, covering correlation, simple regression, independent samples $t$-test, dependent samples $t$-test, one-way Analysis of Variance, and Chi Square. In the design process, both content choices and the sequence of course contents were carefully assessed, along with academic expectations and student needs (Baldwin, 2017).

To ensure the alignment of course instructional pedagogy with the learning outcomes ("Quality Matters," n.d.; Rivenbark \& Jacobson, 2014; Shankararaman \& Elmaleh, 2016), all identified competencies were translated into explicit learning topics and then incorporated into course modules. In each unit, considering the nature of full-time working professionals' schedule, all asynchronous study materials were presented in small topics. Each topic was presented on a PowerPoint lecture video lasting 5-15 minutes. Students could review one or more topics from the list depending on their schedule. This is aligned to the CBE development principle that study materials translated from identified competencies should be explicit and of appropriate length and complexity. The explicit mapping among competencies, learning outcomes, and assessment was carefully considered in this course development. In designing learning activities for each unit, the instructor first used self-assessment quiz to enhance students' understanding on the knowledge base of statistics contents where students were allowed unlimited practice attempts before taking the quiz for a grade. In addition, mini-project assignments with real-world data were utilized to develop students' data-related skills (Horton, 2015). For each assignment, students determined a solution and executed the procedure to implement the solution, where they conducted a statistical test using variables of their choice from a dataset with multiple variables. Allowing students to 
make decisions on variables, instead of designating the variable to use, was to create a real-world scenario so students could practice skills needed in the actual hypothesis testing process and become life-long learners.

In addition, optional weekly synchronous Q\&A live sessions were used in this introductory statistics course to build a sense of online community and enhance instructor immediacy (Williams, 2010). Cundell and Sheepy (2018) pointed out that passive online activities, including videos and readings, may not be as effective as having student working with each other. In this online statistics course, students were offered an optional, synchronous Q\&A session so they could ask questions and share comments with peers "face-to-face" through Adobe Connect. Recordings of Q\&A sessions were shared with the whole class so that all students were able to access Q\&A discussions.

\section{Method and Procedure}

Purposeful sampling method was used in this qualitative study. All 15 students who enrolled in the doctoral-level introductory statistics course in Fall 2017 were invited through email about two months after they completed the course. Students were sent a Qualtrics survey link where they clicked to participate after signing the consent form on the first page. Students were asked to reflect on the learning experiences they had in the Fall 2017 statistics course and to answer five reflection questions, including as many details as possible. Participants' demographic information (i.e., gender, ethnicity, and age) was also collected at the end of the questionnaire. The five open-ended reflection questions are listed below.

1. What was the most effective instructional strategy (such as PowerPoint with lectures, documents, mini-project assignments, weekly Q\&A sessions) that helped you learn?

2. How do you perceive the instructional strategies adopted or the course design in this online course?

3. Were there any other instructional strategies which were not adopted in this course and you used on your own?

4. Were the learning activities helpful for you to learn the concepts/materials? What kind of activity (activities) did you find the most helpful?

5. Do you have any other comments for the course? Please be specific.

Content analysis was used to code participants' reflections in this study. Content analysis has been considered a systematic coding and categorizing approach to analyze textual information to determine patterns of words used, their frequency, relationship, and trends of information (Gbrich, 2007; Mayring, 2000; Nagai, 2015; Stone, 2001). Further, Bloor and Wood (2006) posited that content analysis is designed to examine who says what, to whom, and with what effect. In the current study, content analysis was used to examine what students say about the effectiveness of the course design and instructional strategies used in this introductory statistics course.

\section{Results}

Nine out of 15 students participated in this study with a response rate of $60 \%$. One participant did not complete all five questions but his/her response on Question 1 was recorded for analysis. Age distribution was fairly balanced in this study. Three out of eight (37.5\%) participants were $25-39$; three (37.5\%) were $40-54$; and two (25\%) were 55 or older. There were seven female 
participants (87.5\%) and only one male participant (12.5\%). Six participants $(75 \%)$ self-reported to be White/Caucasian, followed by one Hispanic (12.5\%) and one Mixed (12.5\%).

\section{Perceptions on Effective Instructional Strategies and Course Design}

The first and second research question asked participants to identify the most effective instructional strategies (i.e., PowerPoint with lectures, documents, mini-project assignments, weekly QA sessions) that helped them learn and their perceptions on the instructional strategies and course design. Most of participants considered PowerPoint with lectures as the most effective (see Figure 1) that helped them learn.

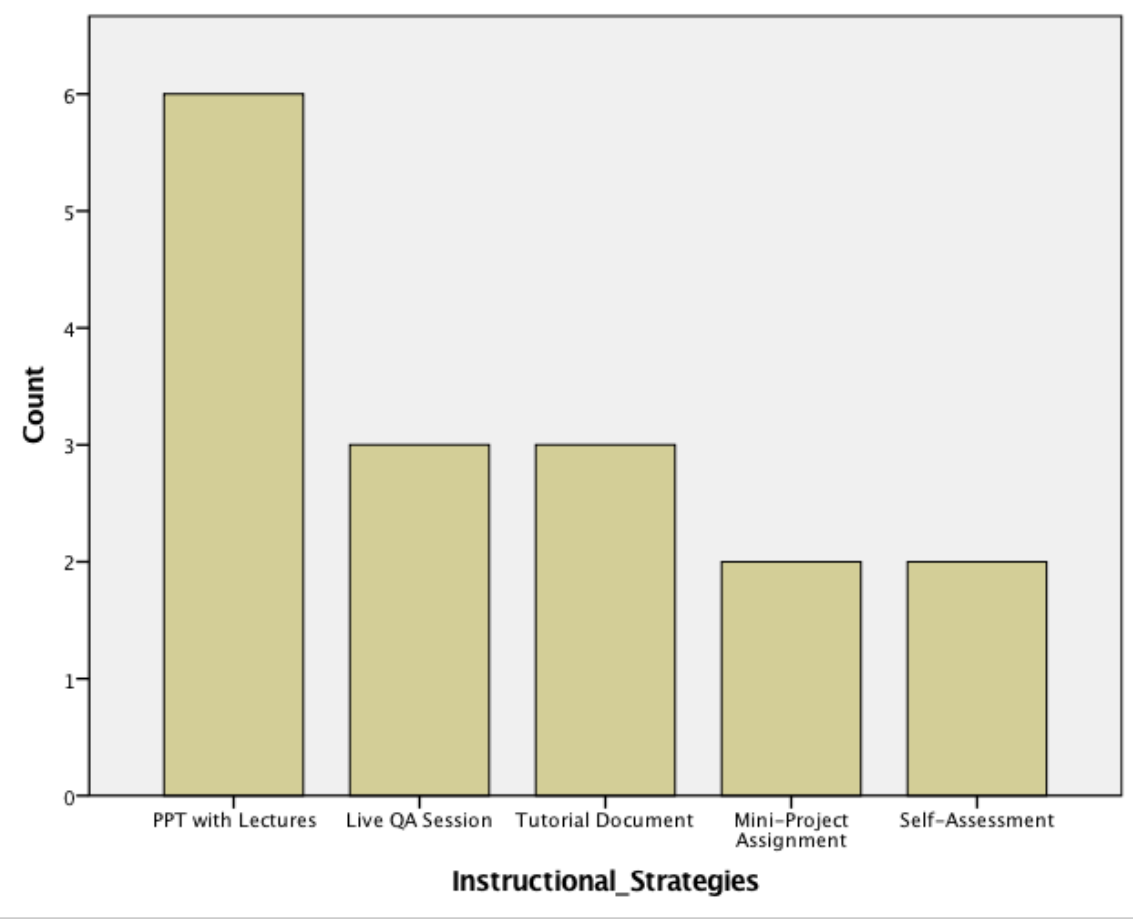

Figure 1. The most effective instructional strategies in students' perception.

One participant noted: "The most beneficial strategies for me were the PowerPoint with video lectures because I was able to go back to them over and over for clarification." Some students actually considered PowerPoint with Lectures and Live QA sessions inseparable and appreciated the design coherency where multiple strategies work together to help them learn. One participant said:

The most effective instructional strategy which helped me to understand and learn statistics was the synchronous online weekly Q\&A session which the professor used to explain her weekly PowerPoint. I realize these are actually two strategies, but I saw them as one. Just reading the PowerPoint was enough for complete understanding. It was the opportunity to ask questions and for Dr. J to more fully explore and explain the PowerPoint that led to my greatest 'ahas. Also, during the online Q\&A session, other students were present and asked some questions which I had not thought of. These explanations provided by Dr. J then broadened my understanding of the statistical concepts for that week. 
Another student saw all instructional strategies as one umbrella strategy and considered the course design as "spiraling of concepts."

Dr. J provided some strategies each week to enhance our understanding of the course content. Each week, the routine of strategies was similar. This was important to me for continuity. The strategies were also in an order in which each strategy built on the next strategy. We were given information first, using both the text and the PowerPoints. We then had the opportunity to ask her questions face-to-face in our mid-week chats. We then had an application exercise to use the information that was presented. In addition, we could take pre-assessments as many times as we needed to understand the concepts. I used each pre-assessment to study the area(s) that I had not mastered. I became comfortable with this routine, and I felt less stress because of it.

One aspect I liked about EDAD 603 was the spiraling of concepts from one lesson to the next. We continued to use the terminology and strategies week to week. Each week in IBM SPSS built upon a previous week. We even got to apply statistical thought to real situations, such as Type I and Type II errors in the context of the justice system. Each week, Dr. J provided additional websites for us to explore.

Other students echoed, "The assignments did well to build off each other. Likewise, the supplementary videos and documents were a great help." "They were consistent each week, which helped maintain pace through each unit. The development of writing was a challenge at the start, but later became more fluid."

On individual instructional strategies, students appreciated Live Q\&A sessions: "The recorded live Q\&A was helpful as Dr. J expanded on the written tutorials. It helped to have both the powerpoint and the recorded Q\&A." Tutorial documents were provided in each unit to provide supplemental materials for students to understand step-by-step statistical procedures and thus, were considered a must-have by many students. Several students indicated that tutorial documents "were very helpful when working through the concepts" and "helped with trying to understand and learn statistics." For the self-assessment/quiz, many students considered it as a great opportunity to practice before earning a grade. A student wrote: "I also appreciated the quizzes being available for practice before taking the real quiz. I would often take a quiz 5-10 times to be sure I understood."

While mini-project assignments were considered "challenging" by many students, one student actually mentioned that "I enjoyed getting to try the cases out on the software (in miniproject assignment)." Another student found the mini-project assignment a necessary step to boost their confidence in the learning process:

The learning activities were especially helpful. The assignments that we completed each week helped me to apply the concepts. The practice with the IBM SPSS program was very beneficial and actually enjoyable. When I completed a weekly assignment, I felt a great sense of accomplishment and understanding. Although I am not sure I recognize every time I should use a particular test, I am much more confident than I was when I began this course.

Some students added "assignment re-do" as an effective instructional strategy used in this course. "While it might not be a specific strategy, I really appreciated that we were sometimes able to re-do assignments. Statistics seemed to build on itself, so going back and doing the work again 
was helpful for those times when I was unsure." Another student wrote: "I felt that the course was well designed. The content was challenging, but I felt that the professor worked very hard to make it as accessible as possible." Many of them believed that the feedback provided on assignment helped them learn beyond the grade they earn: "I appreciate very much the way Dr. J graded our assignments. She highlighted any errors and explained why this was incorrect. We did not just get a grade and then have to figure it out ourselves."

\section{Instructional Strategies Needed and Students' Suggestions}

When asked about instructional strategies that were not adopted in this course and they used on their own, participants listed out self-organized Study Group, supplemental books, YouTube videos, Google, and Khan Academy. In some cases, they conducted google searches not to seek new information on the learning topics but just to enhance understanding from a different perspective. Most students joined voluntary study groups outside of class. Students wrote: "The weekly study groups were also VERY helpful. I would often make changes or adjustments to my assignments as a result of those sessions." "The online study group was very helpful. Occasionally we got to see examples of other students' work during the tutoring group and that helped tremendously." This is especially true when students are sensitive about course grades.

Discovering Statistics Using IBM SPSS Statistics (4th edition) by Andy Field was used in this course. While this book has been popular in statistics teaching with solid, systematic statistics knowledge and a great sense of humor, many students found it "intimidating." To tailor this textbook for educators in this statistics course, the instructor regularly directed students to certain key sections of this book for information. Even so, students still preferred a more hands-on, entrylevel statistics course than Field's. One student wrote: "I did not care for the (Field's) textbook." Tutorial documents that was used to supplement what Field's book lacked were preferred by students: "The textbook chapters provided by Dr. J and the Morgan, Leech, Gloeckner, \& Barrett IBM SPSS for Introductory Statistics (5th ed.) text explained the concepts better than the assigned text when we studied the actual statistical tests."

Students' self-reported emotions toward this statistics course were dichotomous, from one or two students being "frustrated" to some more feeling "enjoyable/beneficial." Some students showed concerns about course grading, whereas other students appreciated the facilitation and assistance received in this course. Some students indicated that they would welcome more APA writing example of statistical tests at the start of the course.

\section{Discussion}

As universities continue to move toward more online learning, it is imperative that faculty members understand and utilize effective instructional strategies in this unique setting. While some researchers argue that online instruction reduces the richness, interaction, and personal touch of the face-to-face classroom, market forces continue to push universities to offer this option to students. When available at this doctoral granting public university in Texas, online program enrollment expands exponentially compared to the traditional classroom setting enrollment. While many faculty members were educated in a traditional brick and mortar university setting, the latest generation of learners expects programs, professional community, and support to be available online. This changing demographic expectation alone drives the need to provide the best instruction possible in an online classroom. Additionally, nearly all students enrolled in 
Educational Administration at the institution studied are full-time school administrators seeking higher education through asynchronous online classroom settings that can be worked into busy lives. The popularity of this program, and its expansion in the past five years, is evidence of the demand for online doctoral programs (THECB, 2018).

The Council of Graduate Schools (1977, cited in Bargar \& Duncan, 1982) posited that the main purpose of doctoral training is "to prepare a student for a lifetime of intellectual inquiry that manifests itself in creative scholarship and research" (p. 1). The dissertation process has been considered the milestone in the scholarship training of students' transition to "independent scholars." Statistics is one of the scheduled tools courses for all doctoral students for degree completion, and knowledge of this subject matter is vital to their transition to independent scholar. However, in the real world, up to $60 \%$ of doctoral students ended up being All But Dissertation (ABD) across the broad (Ehrenberg, Zuckerman, Groen \& Brucker, 2009; Johnson, Green, \& Kluever, 2000), which indicates that the research skills components of the degree may be lacking in the training of doctoral students. Student success in this course is implicated in the measure of departmental graduation goals and the state measures of doctoral programs as outlined in the 18 Characteristics of Doctoral Programs (THECB, 2018). Under such circumstances, the current introductory statistics course was designed in the vein of Competency-Based Education (CBE) with the hope that students could master needed competencies and skills in this research tool class.

Reviewing the study results, it is not surprising that students identified PowerPoint presentations with recorded lectures as the most useful strategy. This strategy, along with other guided practical activities, helped students see how statistics could be applied in their workplace by making the textbook information more real-world and connecting the elements of statistics to applications. As noted by Johnstone and Soares (2014), one thing that separates CBE from others is that it highlights the application of knowledge and skills in the real world. Spady (1977) argued competency in $\mathrm{CBE}$ renders the concept of life-roles beyond institutional education. While theoretical learning is the cornerstone of higher education, CBE could bridge the gap between academics and working fields and a CBE-oriented course design should have a more direct impact on students' success in their work field. The current course focused on relating statistical concepts to real-world applications beyond the textbook through engaging students in real-data projects in assignments. Students' feedback to the current course design revealed that they were enlightened by the connection between statistics and their real work needs. Positive messages from the students confirmed the need for an outcome-oriented statistics course design that gears towards application and empower students' learning.

Students in this study found the spiraling nature of the lessons helpful in developing data habits of minds and providing logical building blocks for difficult subject matter such as statistics (Horton, 2015; Yang, 2017). In this course design, students were instructed to (a) study PowerPoint with Lectures and understand the statistical concept and learn how to perform statistical procedures; (b) study supplemental tutorial documents for step-by-step instructions and interpretation/writing up example; (c) attend or review synchronous live Q\&A sessions (recording) to further their understanding; (d) practice on the statistical concepts in self-assessment/quiz; lastly and more importantly, (e) complete mini-project assignment. In students' learning process, miniproject assignment acted more like a summative achievement test, not a solo strategy. This message was well-received by students and they believed that all instructional strategies functioned with high degree of coherence as one unified umbrella strategy, rather than as separate pieces. As outlined in QM standards ("quality matter," n.d.), the design goal of a quality online 
course is to ensure alignment among the course objectives, the learning activities, instructional materials, and media resources. Based upon the feedback from the students in this study, it seems this goal has been well achieved.

One of the most useful strategies identified by students was the online Q\&A sessions in which students were able to virtually interact with the instructor and peers regarding any questions. Synchronous responses were provided to students' questions and students had the chance to exchange ideas and learn from peers (Cundell \& Sheepy, 2018). Thanks to the cohort structure of the program, students of this class were able to build bonds with each other and form an online learning community easily. Originated from Vygotsky's (1978) social constructivist theories of learning, the Community of Practice (CoP) theoretical framework (Wenger, 1998, 2010; Wenger, Trayner, \& de Laat, 2011) posited that the learning partnership should be established so that people "learn from and with each other about a particular domain" (p. 9) and each individual's experience of practice can be used as a learning resource. Smith, Hayes, and Shea (2017) noted that alternative tools, beyond the most popular discussion board, should be integrated into the design in the online learning practices. Berry (2017) also suggested that a sense of community could be achieved by using technology in various ways, including a welcoming tone and much more. The positive feedback received in the current study revealed that synchronous Q\&A sessions offered through virtual conference tools (e.g., Adobe connect) worked as one effective alternative in building a successful online learning community. More importantly, social, teaching, and cognitive presence were greatly enhanced by this synchronous tool for achieving a deep learning experience in a collaborative-constructive manner (Garrison et al., 2000). Norberg, Stockel, and Antti (2017) posited that synchronicity facilitated online classroom interaction between instructor and students with a feeling of presence and a balanced work rhythm. Many students in this study reported they had a great sense of security after interaction with instructor and peers and gained confidence about statistics towards the end of the course. In a supportive, trusting online learning community, learners were able to identify with the community, develop meaningful intellectual exchange, and achieve desired educational learning outcomes.

One interesting thing found in the participants' responses was their favor towards assignment re-do. Students reported that they saw how statistics started to build on itself in the process of redoing the assignment. They were allowed to try different variables to redo their assignment as in handling dataset in real research scenarios without late penalty. In fact, CBE promotes flexibility and encourages individualization in time (Spady, 1977). Time should be used flexibly in terms of "when, how long, and how often opportunities for both instruction and evaluation are provided" (p. 11). While Spady invited people to reconsider the "usual, fixed" instructional practices in most institutional settings forty years ago, the most recent teaching experience from Rush ("How one professor learned to stop worrying and drop the deadline," 2019) showed us it might not be a bad idea to get rid of rigid grading policies. In teaching first- and second year college students, Rush dropped all course assignment deadlines by telling students that they could turn in assignment late and redo it as many times as needed for a better grade. All due dates were gone except the ultimate due date of 5 p.m. on the Friday before the semester final. As a result, average grades in his courses went up with one or two fewer Fs per class. Active procrastination (Chu \& Choi, 2005) might help us understand Rush's observation. Active procrastination is where an individual, capable of acting on their decision in a timely manner, deliberately chooses to postpone a task and divert attention on to more important ones. Active procrastinators normally enjoy working under pressure, meet deadlines and are satisfied with their outcome (Choi \& Moran, 2009). In Rush's case, students were given the whole semester to better 
understand, and work with, their own time-management and may develop deep learning by managing their time with more flexibility. The feedback received in the current study regarding flexible assignment redo policy echoes Rush's experiment that students actually benefited from being allowed room for learning and growth at their own pace. This might be more important to those learning more difficult subjects, and those with busy lives. Further examinations on how to incorporate time flexibility into online course design, more importantly, to what extent flexibility should be offered, are needed.

\section{Conclusion}

This qualitative study examined doctoral level students' perception of the effectiveness of instructional strategies and course design features of a graduate-level introductory statistics course in a fully online Educational Leadership Doctoral program. The emphasis on competency learning, course design coherence, instructor immediacy, as well as students' confidence towards this statistics course, are evident in students' perceptions. It should be noted that, as this course mainly served doctoral-level students who were full-time professionals in the educational administration field, the conclusions made in this study may not be generalized to other programs with a different student body or other disciplines. Also, the interview questions used in this study were adopted from Yang (2017), where perceptions of students in a teacher training program were examined about their perspectives on the effectiveness of online instructional strategies used in a fully online statistics course. Additional questions could have been added to expand the research scope from different perspectives. For example, future research could explore students' statistics anxiety change before and after course taking and how self-efficacy plays a role in their online learning experiences. Social, teaching, and cognitive presence of CoI could be examined in this statistical online learning community (Garrison et al., 2000). Further research might also explore the textbook in statistics leaning for practitioners. With further research on the application of CBE in online statistics course design, higher education could improve course designs to ensure effective online instruction to meet the market needs. 


\section{References}

Anderson, J. F., \& Norton, R. W., Nussbaum, J. F. (1981). Three investigations exploring relationships between perceived teacher communication behaviors and student learning. Communication Education, 20, 377-392.

Arasaratnam-Smith, L. A., \& Northcote, M. (2017). Community in online higher education: Challenges and opportunities. Electronic Journal of E-Learning, 15(2), 188-198.

Baldwin, S. J. (2017). Adaptation and acceptance in online course design from four-year college and university instructors: An analysis using grounded theory (Doctoral dissertation). Retrieved from http://scholarworks boisestate.edu/td/1241

Baloglu, M. (2003). Individual differences in statistics anxiety among college students. Personality and Individual Differences, 34, 855-865. doi: 10.1016/S0191-8869(02)00076-4

Bargar, R.R., \& Duncan, J.K. (1982). Cultivating creative endeavor in doctoral research. The Journal of Higher Education, 52, 1-31. doi: 10.2307/1981536

Berry, S. (2017). Building community in online doctoral classrooms: Instructor practices that support community. Online Learning, 21(2), doi: 10.24059/olj.v21i2.875

Bloor, M., \& Wood, F., (2006). Keywords in qualitative methods. London: Sage.

Bonk, C. J., \& Dennen, V. P. (2003). Frameworks for research design, benchmarks, training and pedagogy in web-based distance education. In M. G. Moore, W. G. Anderson (Eds.). Handbook of distance education (pp. 245-260). Mahwah, NJ: Lawrence Erlbaum Associates.

Brown, E. N., \& Kass, R. E. (2009). What is Statistics? The American Statistician, 63(2), 105-110.

Carey, E., Hill, F., Devine, A., \& Szücs, D. (2016). The chicken or the egg? The direction of the relationship between mathematics anxiety and mathematics performance. Frontier in Psychology, 6, 1987. doi: 10.3389/fpsyg.2015.01987

Choi, J. N., \& Moran, S.V. (2009). Why not procrastinate? Development and validation of new active procrastination scale. Journal of Social Psychology, 149, 195-211.

Chu, A. H. C., \& Choi, J. N. (2005). Rethinking procrastination: Positive effects of 'active' procrastination behavior on attitudes and performance. Journal of Social Psychology, 145, 245-264.

Cook, C. W., \& Sonnenberg, C. (2014). Technology and online education: Models for change, Contemporary Issues in Education Research, 7(3), 171-188.

Cundell, A., \& Sheepy, E. (2018). Student perceptions of the most effective and engaging online learning activities in a blended graduate seminar. Online Learning, 22(3), 87-102.

doi:10.24059/olj.v22i3.1467 
Ehrenberg, R. G., Zuckerman, H., Groen, J. A., \& Brucker, S. M. (2009). How to help graduate students reach their destination. The Chronicle of Higher Education, p. A38.

Finzer, W. (2015). The data science education dilemma. Technology Innovations in Statistical Education, 7(2). Retrieved from https://escholarship.org/uc/item/7gv0q9dc

Friedman, J. (2018). Study: More students are enrolling in online courses. Retrieved from https://www.usnews.com/higher-education/online-education/articles/2018-01-11/study-morestudents-are-enrolling-in-online-courses? $\mathrm{src}=\mathrm{usn}$ tw

Garrison, D. R., Anderson, T., \& Archer, W. (2000). Critical inquiry in a text-based environment: Computer conferencing in higher education. The Internet and Higher Education, 2(2-3), 87105.

Gbrich C. (2007). Qualitative data analysis: An introduction (1st ed.). London: Sage Publications.

Hamilton, E., \& Feenberg, A. (2012). Alternative rationalisations and ambivalent futures: A critical history of online education. In Andrew Feenberg \& Norm Friesen (Eds.), (Re)inventing the internet. Rotterdam: Sense.

Hopko, D. R., Mahadevan, R., Bare, R. L., \& Hunt, M. K. (2003). The abbreviated math anxiety scale (AMAS): Construction, validity, and reliability. Assessment, 10, 178-182. doi: $10.1177 / 1073191103010002008$

Horton, N. J. (2013). I hear, I forget. I do, I understand: A modified Moore-method mathematical statistics course. The American Statistician, 67(4), 219-228.

Horton, N. J. (2015). Challenges and opportunities for statistic and statistical education: Looking back, looking forward. The American Statistician, 69(2), 138-145.

Horton, N. J., Baumer, B., \& Wickham, H. (2015). Setting the stage for data science: Integration of data management skills in introductory and second courses in statistics, Chance, 28(2), 4050 .

Johnson, E.M., Green, K.E., \& Kluever, R.C. (2000). Psychometric characteristics of the revised procrastination inventory. Research in Higher Education, 41(2), 269-79.

Johnstone, S. M., Soares, L. (2014). Principles for developing competency-based education programs. Change: The Magazine of Higher Learning, 46(2), 12-19. doi: 10.1080/00091383.2014.896705

Kaplan, D. (2012). Statistical Modeling: A Fresh Approach (2 ${ }^{\text {nd }}$ Ed.). Retrieved from http://www.mosaic-web.org/go/StatisticalModeling

Larwin, K., \& Larwin, D. (2011) A meta-analysis examining the impact of computer-assisted instruction on postsecondary statistics education. Journal of Research on Technology in Education, 43(3), 253-278. doi: 10.1080/15391523.2011.10782572 
Lu, F., \& Lemonde, M. (2013). A comparison of online versus face-to-face teaching delivery in statistics instruction for undergraduate health science students. Advance in Health Sciences Education, 18, 963-973. doi: 10.1007/s10459-012-9435-3

Macher, D., Paechter, M., Papousek, I., Ruggeri, K., Freudenthaler, H., \& Arendasy, M. (2013). Statistics anxiety, state anxiety during an examination, and academic achievement. British Journal of Educational Psychology, 83, 535-549. doi: 10.1111/j.2044-8279.2012.02081.x

Mayring P. (2000). Qualitative Content Analysis. Forum: Qualitative Social Research, 1, 20.

Mehrabian, A. (1971). Silent messages. Belmont, CA: Wadsworth

Nagai, A. (2015). Content analysis: It's not bean-counting. Academic Quest, 28, 472-479.

Norberg, A., Stockel, B., \& Antti, M. (2017). Time shifting and agile time boxes in course design. International Review of Research in Open and Distributed Learning, 18(6), 88-103.

Onwuegbuzie, A. (2004). Academic procrastination and statistics anxiety. Assessment Evaluation Higher Education, 29, 3-19. doi: 10.1080/0260293042000160384

Onwuegbuzie, A., \& Daley, C. (1999). Perfectionism and statistics anxiety. Personal Individual Difference, 26, 1089-1102. doi: 10.1016/S0191-8869(98)00214-1

Onwuegbuzie, A., Da Ros, D., \& Ryan, J.M. (1997). The components of statistics anxiety: A phenomenological study. Focus on Learning Problems in Mathematics, 19, 11-35.

Onwuegbuzie, A., \& Wilson, V. (2003). Statistics anxiety: Nature, etiology, antecedents, effects, and treatments - a comprehensive review of the literature. Teaching Higher Education, 8, 195209. doi: $10.1080 / 1356251032000052447$

Passow, H. (2012). Which ABET competencies do Engineering graduates find most important in their work? Journal of Engineering Education, 101(1), 95-108.

Pinto, Y. (2012). A strategy, implementation and results of a flexible competency-based curriculum. ACM Inroads, 1(2), 54-61.

Quality Matters. (n.d.). Retrieved from https://www.qualitymatters.org/

Rivenbark, W. C., \& Jacobson, W. S. (2014). Three principles of competency-based learning: Mission, mission, mission. Journal of Public Affairs Education, 20(2), 181-192.

Saadati, F., Ahmad, R., Mohd, A. F., \& Abu, K. (2015). Effect of internet-based cognitive apprenticeship model (i-CAM) on statistics learning among postgraduate students. PloS One, 10(7), doi:10.1371/journal.pone.0129938

Seaman, J.E., Allen, E., \& Seaman J. (2018). Great increase: Tracking distance education in the United States. Babson Survey Research Group, Retrieved from http://onlinelearningsurvey.com/reports/gradeincrease.pdf 
Shankararaman, V., \& Elmaleh, J. (2016). Leveraging competency framework to improve teaching and learning: A methodological approach. Education and Information Technologies, 21(5), 1299-1327. Retrieved from: http://ink.library.smu.edu.sg/sis_research/2519.

Smith, S. U., Hayes, S., \& Shea, P (2017). A critical review of the use of Wenger's Community of Practice (CoP) theoretical framework in online and blended learning research, 2000-2014, Online Learning, 21(1), 209-237. doi: 10.24059/olj.v21i1.963

Sosa, G., Berger, D., Saw, A., \& Mary, J. (2011). Effectiveness of computer-assisted instruction in statistics: A meta-analysis. Review of Educational Research, 81(1), 97-128. doi:10.3102/0034654310378174

Spady, W. G. (1977). Competency based education: A bandwagon in search of a definition. Educational Research, 6(1), 9-14.

Stone, P. (2001). Content Analysis. In Encyclopedia of Sociology (2nd ed., Vol. 1, pp. 417-422). New York: Macmillan Reference USA. Retrieved from http://link.galegroup.com.proxy.tamuc.edu/apps/doc/CX3404400067/GVRL?u=txshracd2565 $\underline{\text { ssid }=\text { GVRL\&xid }=\mathrm{b} 241 \mathrm{e} 461}$

THECB. (2018, Spring). 2018 Texas Public Higher Education Almanac. Retrieved from http://www.thecb.state.tx.us/reports/PDF/10900.PDF?CFID=86738635\&CFTOKEN=966284 $\underline{09}$

Vygotsky, L. S. (1978). Mind in society. Cambridge, MA: Harvard University Press.

Wenger, E. (1998). Communities of practice: Learning, meaning and identity. New York, NY: Cambridge University Press.

Wenger, E. (2010). Communities of practice and social learning systems: The career of a concept. In C. Blackmore (Ed.), Social Learning Systems and Communities of Practice (pp. 179-198). London: Springer. doi:10.1007/978-1-84996-133-2

Wenger, E., Trayner, B., \& de Laat, M. (2011). Promoting and assessing value creation in communities and networks: A conceptual framework. Heerlen, The Netherlands: Ruud de Moor Centrum, Open University of the Netherlands.

Wickham, H. (2014). Tidy data. Journal of Statistical Software, 59(10). Retrieved from http://www.jstatsoft.org/v59/i10/

Williams, A. S. (2010). Statistics anxiety and instructor immediacy. Journal of Statistics Education, 18(2), doi: 10.1080/10691898.2010.11889495

Yang, D. (2017). Instructional strategies and course design for teaching statistics online: Perspectives from online students. International Journal of STEM Education, 4(1). doi:10.1186/s40594017-0096-X 